\title{
Introducing the nanoworld
}

\author{
Themis Prodromakis explains how to engage primary school students in nanotechnology — even outside \\ the classroom.
}

ectures are probably the oldest form of science outreach, dating back to the 1820s when Faraday organized the first of the Royal Institution's Christmas Lectures (http://www.rigb.org/christmas-lectures). However, the best way to inspire someone about our job as researchers is by actively sharing the feeling of joyousness when a scientific discovery occurs - the priceless moment that makes us persist working despite the many challenges we come across. This is particularly the case if outreach is to enhance young people's attendance, attainment and achievement in science. For this aim, we need to start early in engaging young students with hands-on scientific experiments, as well as equipping them with a glimpse of realism. Presenting the related challenges and constraints in an intriguing perspective could avoid intimidation when their time comes to step into a career in science.

Through taught and research programmes, the University of Southampton is committed to developing the next generation of nanotechnologists, organizing practical lab experiences that take place in our multimillion-pound state-of-the-art cleanroom facilities. However, this privilege comes at a certain cost, and requires a certain maturity to comprehend complex nanoconcepts. Our outreach team in the Nanoelectronics and Nanotechnology Group at the University of Southampton has attempted to break the problem down into its constituents, allowing us to bring the nanoscale world and its importance (see The Conversation, 22 March 2016; http://go.nature.com/2uq8J6u) to a level that is both entertaining and understandable even to primary school students. The main objective of our outreach activity is to pique their curiosity by taking them through a typical working pattern for designing, developing and testing a new device. To make this even more challenging, it all has to be delivered without requiring access to a highly controlled environment such as a cleanroom.

Cleanroom gowning is a routine part of a nanotechnologist's day. However, it usually raises alarming concerns about potential health risks for the workers. The first aim of our activity is then to make the students fully appreciate the true meaning of a cleanroom: this is an area that is maintained free of contaminants, such as dust or bacteria, allowing us to develop high-precision patterns and devices. Realizing that cleanroom suits essentially protect the environment from us (as opposed to the other way around) changes the perspective, and students turn out to be keen to master this process that will grant them access to a restricted area. This turns an otherwise boring routine into a fascinating experience, with the students excited to dress up in kidsized cleanroom suits, masks and gloves that they all keep at the end.

Photolithography - whose root words photo, litho and graphy are Greek in origin and correspond to light, stone and writing is a common manufacturing technique in which light is used to transfer a pattern onto a substrate. In our demonstrations, we replace expensive Si wafers, photoresists and highprecision lithography masks with acrylic (PMMA) substrates laminated with photopatternable films (dry photoresist), while laser-printed transparencies play the role of the photolithography masks - all prepared in advance. At first, each student chooses a transparency mask from a selection of patterns ranging from images of the ancient Phaistos disc - one of the first actual lithographies on stone - to their favourite superheroes. They attach these to the pre-laminated plastic samples and load them onto a mobile ultraviolet lamp for a timed exposure. The moment of discovery occurs when these invisible patterns start to appear through development in soda water. At the end of this experience, the students clean the samples, inspect them under a microscope and keep them as souvenirs.

Nanomaterials provide us with new application opportunities - for instance, in flexible and printed electronics. We give the students an example by using pens whose ink is loaded with silver nanoparticles to form conductive paths on a maze printed on paper. Painting the correct path turns on a lightemitting diode by connecting it to a battery source. The students also learn other exciting applications enabled by nanomaterials, ranging from sensors and solar cells, to touch screens and displays, and printed radiofrequency identification tags.

Microscopes are essential instruments to inspect nanotechnology products. A simple tabletop high-definition digital microscope is used throughout our outreach activities

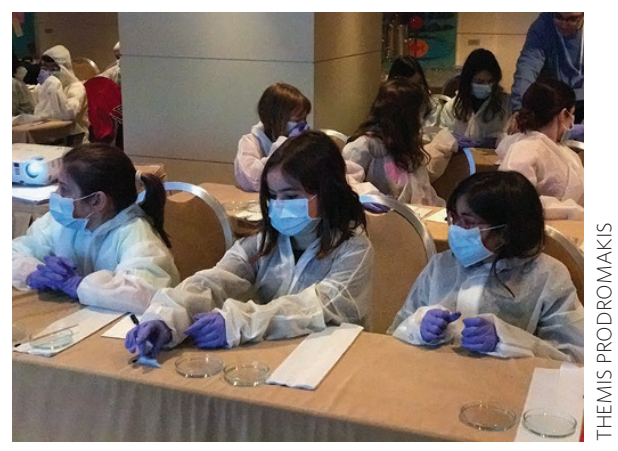

to visualize the lithography-developed samples and explain the working principles of smartphones and tablets. The students observe the components of touch screens under the microscope and visualize how single lightemitting diodes are switched on and off to render images.

These activities were developed and optimized over the past few years thanks to a large number of volunteering graduate students and members of our research group, and have been exposed to the general public at university open-days. In April 2017, we further showcased the versatility of this approach by venturing an international nanotechnology outreach event supported by the Lloyd's Register Foundation (http://www.lrfoundation.org.uk) and held at the Intercontinental Hotel in Athens. Here, all the activities mentioned above - organized and run by Southampton $\mathrm{PhD}$ students Isha Gupta and Nikolaos Vasilakis, with the assistance of Dr Loukas Michalas and George Papandroulidakis - involved about 150 school children aged 8-15 (pictured). We were thrilled to see that both the students and their teachers enjoyed the day and gave us great feedback, with some students saying they "understand what nano brings to our future life", that it was "one of the best school trips" and, most importantly, that they "will start thinking of studying physics" or "would love to study nanotechnology in cooperation with medicine".

\section{THEMIS PRODROMAKIS is in the} Department of Electronics and Computer Science, University of Southampton, Southampton SO17 1BJ, UK, and Director of the Lloyd's Register Foundation International Consortium for Nanotechnologies. e-mail: t.prodromakis@soton.ac.uk 